\title{
Low cerebral blood flow is a risk factor for severe intraventricular haemorrhage
}

\author{
Judith H Meek, Lidia Tyszczuk, Clare E Elwell, J S Wyatt
}

\begin{abstract}
Aims-To investigate the relation between cerebral blood flow on the first day of postnatal life and the severity of any subsequent germinal matrix haemorrhageintraventricular haemorrhage (GMHIVH).

Methods-Cerebral blood flow was measured in 24 babies during the first 24 hours of life using near infrared spectroscopy. Repeated cerebral ultrasound examination was performed to define the maximum extent of GMH-IVH. Infants were classified as: normal scan, minor periventricular haemorrhage (haemorrhage that resolved), or severe GMH-IVH (haemorrhage distending the ventricles, that progressed to either post haemorrhagic dilatation or porencephalic cyst formation).

Results-Cerebral blood flow was significantly lower in the infants with GMH-IVH (median $7.0 \mathrm{ml} / 100 \mathrm{~g} / \mathrm{min}$ ) than those without haemorrhage (median $12.2 \mathrm{ml} / 100$ g/min), despite no difference in carbon dioxide tension and a higher mean arterial blood pressure. On subgroup analysis, those infants with severe GMH-IVH had the lowest cerebral blood flow.

Conclusion-A low cerebral blood flow on the first day of life is associated with the subsequent development of severe intraventricular haemorrhage.
\end{abstract}

(Arch Dis Child Fetal Neonatal Ed 1999;81:F15-F18)

Keywords: intraventricular haemorrhage; cerebral blood flow; cerebral ischaemia; near infrared spectroscopy

Germinal matrix haemorrhage-intraventricular haemorrhage (GMH-IVH) in preterm neonates carries an increased risk of neurodevelopmental morbidity if it is associated with either post haemorrhagic ventricular dilatation (PHD) or haemorrhagic parenchymal infarction (HPI). ${ }^{1}$ These lesions may follow early abnormalities of cerebral blood flow (CBF), and the risk of GMH-IVH is greatest during the first three days of life. ${ }^{2}$ This study aimed to relate $\mathrm{CBF}$ measured during the first 24 hours of life to the incidence and severity of any subsequent GMH-IVH.

\section{Methods}

We studied extremely preterm infants on the first day of postnatal life after admission to the University College London Hospitals Trust neonatal intensive care unit. Twenty four infants were studied. Ethical permission for the study was obtained from the local ethics committee, and informed consent was obtained from one or both parents of each infant before the study. Infants who had been electively delivered on the basis of abnormal antenatal umbilical artery pulsations measured by Doppler ultrasonography were excluded, because their cerebral haemodynamics were likely to have been abnormal. Due to methodological limitations we were unable to study infants ventilated in air, which excluded those ventilated using the high frequency oscillator, or infants requiring $100 \%$ oxygen.

The median gestational age was 26 weeks (range 24 to 31 weeks), and the median birth weight was $873 \mathrm{~g}$ (range 620 to $1470 \mathrm{~g}$ ). All infants were appropriately grown for gestational age. All were ventilated with supplementary oxygen using intermittent positive pressure ventilation. Two were receiving infusions of dopamine and/or dobutamine to treat hypotension. Clinical details are given in table 1 .

Cerebral blood flow was measured using near infrared spectroscopy (NIRS) ${ }^{3}$ during the first day after delivery, at a median (range) age of 19 (5-24) hours. Measurements were obtained using a commercial spectrophotometer (NIRO500, Hamamatsu Photonics KK, Japan). Near infrared light from four laser diodes was transmitted via a fibre optic bundle to an "optode" on the tempero-parietal or frontal region of the infant's head. A detecting optode, placed 4-5 $\mathrm{cm}$ away on the opposite side of the head, was connected to a second fibre optic bundle which conveyed the emerging light to the spectrophotometer. A computer converted the changes in optical density into changes in cerebral concentration of oxyhaemoglobin $\left(\mathrm{HbO}_{2}\right)$, and deoxyhaemoglobin from an arbitrary baseline. Arterial oxygen saturation $\left(\mathrm{SaO}_{2}\right)$, mean arterial blood pressure (MABP), partial pressure of carbon dioxide $\left(\mathrm{PaCO}_{2}\right)$ and heart rate were simultaneously recorded.

Cerebral blood flow was determined from the Fick principle, using $\mathrm{HbO}_{2}$ as an intravascular tracer. A rapid rise in $\mathrm{SaO}_{2}$ was induced by a step increase in $\mathrm{FIO}_{2}$. Cerebral blood flow $(\mathrm{ml} / 100 \mathrm{~g} / \mathrm{min})$ was then calculated from the integral of the saturation rise and the rate of rise of tracer concentration using the equation:

$$
\mathrm{CBF}=\mathrm{k} \cdot \Delta[\mathrm{HbO} 2] /\left(\mathrm{H} \cdot \int \Delta \mathrm{SaO}_{2} \cdot \mathrm{dt}\right)
$$

where $\mathrm{k}$ is a constant (0.0614) incorporating brain tissue density and the molecular weight of haemoglobin and $\mathrm{H}$ is the large vessel haemoglobin concentration $(\mathrm{g} / \mathrm{dl})$. 
Table 1 Clinical details and ultrasound diagnoses of infants studied

\begin{tabular}{|c|c|c|c|c|c|c|c|}
\hline Group & Infant & Gestational age & $\begin{array}{l}\text { Birth weight } \\
\text { SDS }\end{array}$ & Diagnosis & Inotropes & Clinical outcome & $\begin{array}{l}\text { Cranial ultrasound diagnosis, with day } \\
\text { haemorrhage first noted }\end{array}$ \\
\hline \multirow[t]{17}{*}{1} & 1 & 24 & 1.29 & Mild HMD & No & No major problems & Normal \\
\hline & 2 & 28 & 0.50 & PROM, mild HMD & No & No major problems & Normal \\
\hline & 3 & 25 & -0.07 & HMD & No & No major problems & Normal \\
\hline & 4 & 29 & -1.34 & Triplet I & No & No major problems & Normal \\
\hline & 5 & 27 & -0.42 & Twin I & $\begin{array}{l}\text { Dopamine at } \\
10 \mu \mathrm{g} / \mathrm{kg} / \mathrm{min}\end{array}$ & No major problems & Normal \\
\hline & 6 & 27 & -0.38 & HMD & No & No major problems & Normal \\
\hline & 7 & 24 & -1.07 & HMD & No & No major problems & Normal \\
\hline & 8 & 28 & -0.84 & Severe HMD and PIE & No & Mild spastic diplegia & Normal \\
\hline & 9 & 24 & -0.48 & Severe HMD and PIE & No & Died day 5, PIE & Normal \\
\hline & 10 & 25 & -1.07 & HMD & No & No major problems & Normal \\
\hline & 11 & 26 & 1.29 & Severe HMD & No & No major problems & Normal \\
\hline & 12 & 28 & -0.97 & Mild HMD & No & No major problems & Normal \\
\hline & 13 & 28 & -0.91 & Mild HMD & No & No major problems & Normal \\
\hline & 14 & 31 & -0.13 & Moderate HMD & No & Emigrated, no follow-up & Normal \\
\hline & 15 & 30 & 0.57 & Mild HMD & No & No major problems & Normal \\
\hline & 16 & 27 & -0.94 & Maternal PIH, mild HMD & No & No major problems & Normal \\
\hline & 17 & 25 & 1.33 & $\begin{array}{l}\text { Maternal streptococcal } \\
\text { chorioamnionitis }\end{array}$ & No & No major problems & $\begin{array}{l}\text { No haemorrhage, late small } \\
\text { periventricular cyst }\end{array}$ \\
\hline \multirow[t]{2}{*}{2} & 18 & 25 & 0.35 & $\begin{array}{l}\text { Maternal candidiasis, mild } \\
\text { HMD }\end{array}$ & No & No major problems & Left GLH, right small IVH day 1 \\
\hline & 19 & 26 & -0.58 & Maternal PIH, mild HMD & No & No major problems & Right GLH day 2 \\
\hline \multirow[t]{5}{*}{3} & 20 & 29 & 0.68 & Twin 2, mild HMD & No & Diplegia, esotropia & Bilateral large IVH with PHD day 2 \\
\hline & 21 & 26 & -0.44 & Severe HMD and PIE & No & $\begin{array}{l}\text { Hemiplegia, } \\
\text { developmental delay } \\
\text { Convulsions }\end{array}$ & $\begin{array}{l}\text { Left HPI, leading to porencephalic cyst } \\
\text { Right small IVH day } 2\end{array}$ \\
\hline & 22 & 27 & 0.72 & HMD & No & Hemiplegia, asthma & $\begin{array}{l}\text { Left HPI, leading to porencephalic cyst } \\
\text { Right large IVH day } 1\end{array}$ \\
\hline & 23 & 24 & -0.14 & Twin 1, HMD & No & Developmental delay & Left HPI and right large IVH, PHD day 2 \\
\hline & 24 & 24 & 0.04 & $\begin{array}{l}\text { Twin 2, severe } \mathrm{HMD} \text {, renal } \\
\text { failure }\end{array}$ & $\begin{array}{l}\text { Dopamine, } \\
\text { dobutamine }\end{array}$ & Died day 5 & Left large IVH, right HPI, PHD day 3 \\
\hline
\end{tabular}

Abbreviations: HMD, hyaline membrane disease; PIE, pulmonary interstitial emphysema.

For each infant six measurements of $\mathrm{CBF}$ were attempted. Only those measurements were accepted that met previously established criteria for the stability of parameters such as the $\mathrm{PaCO}_{2}, \mathrm{MABP}$, and $\left[\mathrm{Hb}+\mathrm{HbO}_{2}\right]$ during the measurement, and the stability of the $\mathrm{SaO}_{2}$ baseline before the saturation swing. ${ }^{4}$ The mean value of the measurements which met the acceptance criteria was used for analysis. Between two and six successful measurements were achieved for each infant.

Cerebral ultrasound examination was performed daily for the first week of life, and then at least once a week until term or death. Scans were recorded and carefully classified by independent observers who were blind to the cerebral blood flow results. All infants had a normal appearance on cranial ultrasound examination at the time of study.

Infants were ascribed to outcome groups according to the maximum extent of the appearance of their cranial ultrasound scans. Group 1 had normal scans and group 2 had evidence of minor GMH-IVH which later resolved leaving a normal scan appearance. Group 3 had large GMH-IVH, distending the ventricles, progressing either to PHD or HPI with subsequent porencephalic cyst formation. The CBF, $\mathrm{PaCO}_{2}, \mathrm{MABP}$ and age of each group at the time of study were compared with the others using the Kruskal-Wallis one way analysis of variance (SPSS). As the numbers of infants in groups 2 and 3 were small, the same parameters were compared between the normal group (1) and all infants with GMH-IVH (groups 2 and 3 combined) using the Mann-Whitney test.

\section{Results}

Seventeen of the 24 infants had normal appearances on cranial ultrasound examination (group 1). Two had minor haemorrhages (group 2), and one of these developed a small unilateral parenchymal cyst. Five had severe haemorrhages (group 3). The individual diagnoses and times of onset of the haemorrhage for each infant in groups 2 and 3 are shown in table 1. The timings of the maximum extent of the lesions ranged between 2 and 14 days. The median (range) $\mathrm{CBF}$ of infants in group 1 was $12.2 \mathrm{ml} / 100 \mathrm{~g} / \mathrm{min}(6.1-24.7)$, in group $2,12.0$ $\mathrm{ml} / 100 \mathrm{~g} / \mathrm{min}$ (10.3-13.8), and in group 3 was $5.8 \mathrm{ml} / 100 \mathrm{~g} / \mathrm{min}$ (3.2-7.5). Cerebral blood flow was significantly lower in infants with any GMH-IVH (groups 2 and 3) than in infants without lesions (group 1) ( $p<0.04$, MannWhitney U test), and was significantly lower in group 3 on subgroup analysis $(\mathrm{p}<0.01$, Mann-Whitney U test), but not in group 2 . There was a significant decrease in CBF with group number $(p=0.02$ by KruskalWallis one way Anova). Figure 1 shows the distribution of $\mathrm{CBF}$ over the three groups. There was no significant difference between the $\mathrm{PaCO}_{2}$, gestational age, age at the time of study, inspired oxygen fraction or mean airway pressure of each group. There was a positive trend between MABP and group number ( $p=0.05$, KruskalWallis), and MABP values in group 3 were significantly higher than those in group $1(\mathrm{p}<0.02$ Mann Whitney U test). These results are summarised in table 2 . Figure 2 shows the distribution of MABP over the three groups.

\section{Discussion}

Cerebral blood flow measured during the first 24 hours of life was lower in infants who subsequently developed severe GMH-IVH compared with those who did not develop haemorrhages.

All clinically feasible methods for $\mathrm{CBF}$ measurement in newborn infants have methodological limitations. The $\mathrm{HbO}_{2}$ technique for 


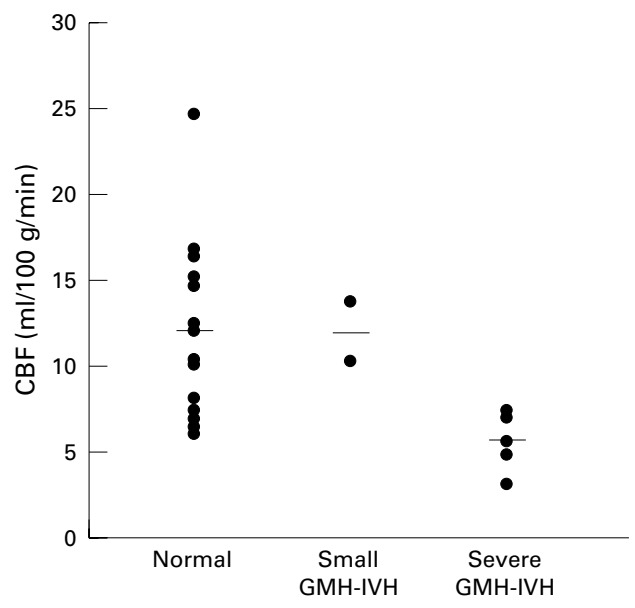

Figure 1 Comparison of cerebral blood flow for the three groups.

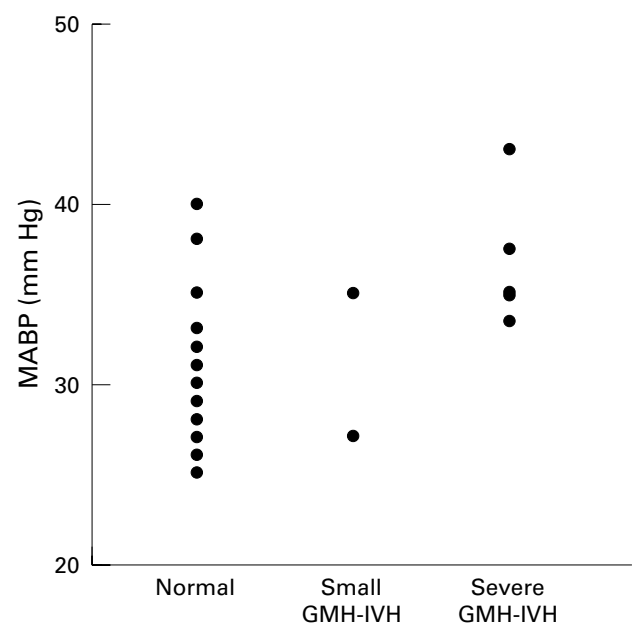

Figure 2 Comparison of $M A B P$ for the three groups.

measuring $\mathrm{CBF}$ has been validated against the intravenous ${ }^{133}$ Xenon clearance method. ${ }^{56}$ The assumptions underlying the method have been discussed elsewhere. ${ }^{7}$ It is reasonable to assume that our results reflect genuine differences in cerebral perfusion between the different study groups.

The range of $\mathrm{CBF}$ values in each group was wide. This may, in part, reflect the fact that measurements were performed over short time periods, and were obtained at different times within the first day of life. Repeated measurements of CBF standardised for time over the first 24 hours would probably yield a more detailed picture of changes in cerebral perfusion which precede the development of GMH-IVH. There was no significant difference in $\mathrm{PaCO}_{2}$, gestational age, or postnatal age at the time of study between the groups. MABP was significantly higher in the infants who developed severe GMH-IVH compared with those without haemorrhage.

Table 2 Results for each group (median and range)

\begin{tabular}{llllll}
\hline Group & $\begin{array}{l}\mathrm{CBF} \\
(\mathrm{ml} / 100 \mathrm{~g} / \mathrm{min})\end{array}$ & $\begin{array}{l}\mathrm{MABP} \\
(\mathrm{mm} \mathrm{Hg})\end{array}$ & $\begin{array}{l}\mathrm{PaCO}{ }_{2} \\
(\mathrm{kPa})\end{array}$ & $\begin{array}{l}\text { Age at study } \\
\text { (hours) }\end{array}$ & $\begin{array}{l}\text { Gestational age } \\
\text { (weeks) }\end{array}$ \\
\hline 1 & $12.1(6.1-24.7)$ & $29.5(25-40)$ & $5.6(3.8-7.6)$ & $15(6-24)$ & $27(24-31)$ \\
2 & $12.0(10.3-13.8)$ & $31.0(27-35)$ & $5.2(5.2-6.3)$ & $12.5(12-13)$ & $25.5(25-26)$ \\
3 & $5.8(3.2-7.5)$ & $35.0(35-43)$ & $5.6(4.9-5.8)$ & $20(8-17)$ & $26(24-29)$ \\
\hline
\end{tabular}

Since the seminal contribution of Pape and Wigglesworth, ${ }^{8}$ cerebral ischaemia has been suggested as an important factor in the pathophysiology of GMH-IVH. Hypoperfusion of the germinal matrix is thought to lead to an impairment in the integrity of the vascular endothelium. A subsequent period of reperfusion leads to an abrupt increase in intravascular pressure, causing haemorrhage within the germinal matrix. It is thought that the extent and position of the haemorrhage determine the likelihood of major complications such as progression to HPI or PHD. The vulnerability of the germinal matrix to hypoperfusion may be due to its watershed vascular supply, or to the higher metabolic rate of its endothelium. ${ }^{9}$ Low CBF during the first day of life may damage the germinal matrix in a way that preconditions it to haemorrhage.

The concept that GMH-IVH was due to an ischaemia/reperfusion sequence was reinforced by the work of Goddard-Finegold and colleagues in a newborn beagle model. They showed that intraventricular haemorrhage occurred in animals exposed to rapid volume expansion, only if it was preceded by hypotension. ${ }^{10}$

GMH-IVH is associated with several factors, especially prematurity, the presence of lung disease and a requirement for mechanical ventilation. ${ }^{11}{ }^{12}$ The association may be mediated by fluctuations in arterial oxygen and carbon dioxide tensions, and in arterial pressure, leading to periods of intermittent ischaemia interspersed with episodes where reperfusion occurs. This may be exacerbated by immaturity of cerebral autoregulation. ${ }^{13}{ }^{14}$ Mechanical ventilation and pneumothorax are also associated with fluctuations in intrathoracic pressure which may be transmitted to the cerebral venous system.

Perlman and colleagues, using Doppler ultrasound, showed an association between fluctuations in blood flow velocity in the anterior cerebral artery and the subsequent development of intraventricular haemorrhage,${ }^{15}$ but other workers have failed to reproduce their observations. ${ }^{16}$

Although rapid fluctuations in cerebral perfusion may predispose to haemorrhage, it is also likely that a prolonged episodes of hypoperfusion may cause vascular injury and programme the germinal matrix towards subsequent haemorrhage.

Ment et al have shown that infants who sustain GMH-IVH during the first 6 hours of life have lower CBF (measured by inhalation ${ }^{133} \mathrm{Xe}$ clearance) than both those who subsequently develop haemorrhage, and those with normal scans. ${ }^{17}$ They have suggested that the lower CBF may be due to the presence of the haemorrhage itself.

The possibility that a cerebral "steal" phenomenon through a patent ductus arteriosus may contribute to the pathogenesis of GMH-IVH has been proposed by Evans and Kluckow, ${ }^{18}{ }^{19}$ based on observations that large early PDA shunts are significantly associated with $\mathrm{GMH}-\mathrm{IVH},{ }^{20}$ and that a PDA can be 
associated with reversed flow velocity in the anterior cerebral arteries, ${ }^{21}$ and the descending aorta. ${ }^{22}$ They measured superior vena cava (SVC) flow $^{19}$ as well as the degree of ductal and atrial shunting using Doppler echocardiography at 5,12, 24 and 48 hours of age in a group of very preterm babies. They found that lower SVC flow at 5 and 12 hours of age was significantly related to subsequent haemorrhage, and was associated with large ductal diameter. SVC flow tended to increase after 12 hours of age coinciding with the appearance of cranial ultrasound evidence of haemorrhage.

The concept that a cerebral steal phenomenon precedes the development of GMH-IVH may explain the reduction in the incidence and severity of haemorrhage following the early administration of indomethacin. ${ }^{23}$ This effect contrasts with the decrease in $\mathrm{CBF}$ which is seen when indomethacin is used for late closure of PDAs. ${ }^{24}$ By combining measurements of $\mathrm{CBF}$ and ductal shunting during the first few hours of life, it may be possible to identify the subgroup of infants who would benefit from treatment with indomethacin, and avoid subjecting the remaining infants to its potential adverse effects.

Further evidence suggests that a PDA, rather than being a cause of cerebral ischaemia, may be a compounding influence. Evans and Kluckow $^{25}$ have shown an inverse relation between SVC flow and upper body vascular resistance. Low CBF resulting from the immature myocardium adapting to extrauterine vascular resistances, is further compromised by ductal steal.

Our findings are consistent with the hypothesis that cerebral ischaemia is an important predisposing factor in the development of severe GMH-IVH. Interestingly, there was no difference in $\mathrm{PaCO}_{2}$ among the study groups, and MABP was higher in those infants with low CBF. It is not clear, therefore, why $\mathrm{CBF}$ was impaired in the adverse outcome group. Although we did not perform echocardiography at the time of study, and no infants had obvious clinical evidence of ductal shunting, a cerebral steal phenomenon might have contributed to the low CBF. Further studies are urgently required to investigate the relation between clinically silent ductal shunting $^{26}$ and cerebral perfusion in the critical period immediately after birth when programming of GMH-IVH may occur.

This study was funded by the Medical Research Council. We thank Dr Ann Stewart, Professor David Edwards, Dr David McCormick, Dr Vincent Kirkbride and Ms Jan Townsend for their contribution to this work. We are grateful to Dr Jane Hawdon and Dr Nick Evans for valuable discussions.
1 Roth SC, Baudin J, McCormick DC, et al. Relation between ultrasound appearance of the brain of very preterm infants and neurodevelopmental impairment at eight years. Dev Med Child Neurol 1993;35:755-68.

2 Thorburn RJ, Lipscomb AP, Stewart AL, Reynolds EOR, Hope PL. Timing and antecedents of periventricular haemorrhage and of cerebral atrophy in very preterm infants. Early Hum Dev 1982; 7:221-38.

3 Edwards AD, Wyatt JS, Richardson C, Delpy DT, Cope M, Reynolds EOR. Cotside measurement of cerebral blood flow in ill newborn infants by near infrared spectroscopy. Lancet 1988;ii: 770-1.

4 Elwell CE. A practical user's guide to near infrared spectroscopy. Japan: Hamamatsu Photonics, 1995.

5 Bucher HU, Lipp AF, Duc D, Edwards AD. Comparison between ${ }^{133}$ Xenon clearance and near infrared spectroscopy for estimation of cerebral blood flow in sick preterm infants. Pediatr Res 1993; 33:56-60

6 Skov L, Pryds O, Greisen G. Estimating cerebral blood flow in newborn infants: comparison of near infrared spectrosin newborn infants: comparison of near infrared spect

7 Elwell CE, Cope M, Edwards AD, Wyatt JS, Reynolds EOR, Delpy DT. Measurement of cerebral blood flow in adult humans using near infrared spectroscopy - methodology and possible errors. Adv Exp Med Biol 1992;317:235-45.

8 Pape KE, Wigglesworth JS. Haemorrhage, ischaemia and the perinatal brain. In: Clinics in Developmental Medicine 69/70 London: SIMP/Heinemann, 1979.

9 Volpe JJ. Neurology of the Newborn. 3rd Edn. Philadelphia: W B Saunders \& Co, 1995: 418.

10 Goddard-Finegold J, Armstrong D, Zeller RS. Intraventricular haemorrhage following volume expansion after hypovolaemic hypotension in the newborn beagle. $f$ Pediatr 1982;100:796-9.

11 Levene MI, Fawer CL, Lamont RF. Risk factors in the development of intraventricular haemorrhage in the preterm neonate. Arch Dis Child 1982; 57:410-17.

12 Harrison VC, Heese $\mathrm{H}$, Klein $\mathrm{M}$. Intracranial haemorrhage associated with hyaline membrane disease. Arch Dis Child 1968;43:116-20.

13 Pryds O. Control of the cerebral circulation in the high-risk neonate. Ann. Neurol 1991 30;321-9.

14 Miall-Allen VM, De Vries LS, Whitelaw AGL. Mean arterial blood pressure and neonatal cerebral lesions. Arch Dis Child 1987;62:1068-9

15 Perlman JM, McMenamin JB, Volpe JJ. Fluctuating cerebral blood-flow velocity in respiratory distress syndrome. Relation to the development of intraventricular haemorrhage. N Engl f Med 1983;309:204-9.

16 Miall-Allen VM, de Vries LS, Dubowitz LMS, Whitelaw AGL. Blood pressure fluctuations and intraventricular haemorrhage in the preterm infant of less than 31 weeks' hestation. Pediatrics 1989;83:657-61.

17 Ment LR, Duncan CC, Ehrekranz RA, et al. Intraventricular haemorrhage in the preterm neonate: timing and cerebral blood flow changes. F Pediatr 1984;104:419-25.

18 Evans NJ, Kluckow $M$ The haemodynamic basis of intraventricular haemorrhage (IVH). Pediatr Res 1997;43:173A

19 Evans NJ, Kluckow M. Early determination of right and left ventricular output in ventilated preterm infants. Arch Dis Child 1996;74:F88-94.

20 Evans N, Kluckow M. Early ductal shunting and intraventricular haemorrhage in ventilated preterm infants. Arch Dis Child 1996; 75:F183-6.

21 Perlman JM, Hill A, Volpe JJ. The effect of patent ductus arteriosus on flow velocity in the anterior cerebral arteries ductal steal in the premature infant. F Pediatr 1981; 99:767-71.

22 Lipman A, Serwer GA, Brazy JE. Abnormal cerebral haemodynamics in pretrm infants with patent ductus arteriosus Pediatr 1982; 69:778-81.

23 Ment LR, Oh W, Ehrenkranz RA, et al. Low dose indomethacin and prevention of intraventricular haemorrhage: a multicenter randomized trial. Pediatrics 1994;93:543-50.

24 Edwards AD, Wyatt JS, Richardson C, et al. Effects of indomethacin on cerebral haemodynamics in very preterm infants. Lancet 1990;335:1491-5.

25 Evans N, Kluckow M. Low upper body and cerebral blood flow in the preterm infant. Pediatr Res 1998;43:173A.

26 Skelton R, Evans N, Smythe J. A blinded comparison of clinical and echocardiographic evaluation of the preterm infant for patent ductus arteriosus. $\mathcal{F}$ Paediatr Child Health 1994;30:406-11. 